This is the post peer-review accepted manuscript of:

Bellettini, G., Taddei, F., Zanella, G., Intergenerational altruism and house prices: evidence from bequest tax reforms in Italy, European Economic Review, http://dx.doi.org/10.1016/j.euroecorev.2016.11.006

(C2016. This manuscript version is made available under the CC-BY-NC-ND 4.0 license http://creativecommons.org/licenses/by-nc-nd/4.0/ 


\title{
Intergenerational altruism and house prices: evidence from bequest tax reforms in Italy*
}

\author{
Giorgio Bellettini ${ }^{\dagger} \quad$ Filippo Taddei ${ }^{\ddagger} \quad$ Giulio Zanella ${ }^{\S}$
}

November 25, 2016

\begin{abstract}
The degree of intergenerational altruism is estimated in a benchmark Barro-type OLG framework with imperfect altruism, exploiting the exogenous variation generated by reforms of the tax treatment of bequests and inter vivos real estate donations enacted in Italy between 2000 and 2001. Using longitudinal information on the housing stock and house prices in 13 large Italian cities between 1993 and 2004, the structural parameter of interest is estimated via the effect of the reform on house prices. We estimate a degree of intergenerational altruism ranging between 0.2 and 0.3 , a magnitude consistent with existing parametrization for the US economy. This suggests that intergenerational altruism may be similar across advanced economies.
\end{abstract}

Keywords: bequests, intergenerational altruism, inheritance tax, gift tax, house prices JEL codes: E60, E65, H24

\section{Introduction}

The degree of intergenerational altruism is a key parameter in dynamic models with overlapping generations, a framework that is widely used in macroeconomics to analyze a variety of questions such as fiscal policy, taxation, and social security. However, only a few estimates of such parameter exist, and they are typically based on incidental indirect inference conducted in the course of calibration exercises for the US economy (e.g., Han and Mulligan, 2001, Nishiyama, 2002, and

\footnotetext{
${ }^{*}$ We are grateful to NOMISMA for its proprietary data base on house prices, the Italian Ministry of the Economy for providing bequest and donation data, as well as two anonymous referees and John Kennan for useful comments.

${ }^{\dagger}$ University of Bologna and CESifo. E-mail: giorgio.bellettini@unibo.it

${ }^{\ddagger}$ SAIS - The Johns Hopkins University and Collegio Carlo Alberto. E-mail: ftaddei@ jhu.edu

$\S$ University of Bologna. Corresponding author. Department of Economics, Piazza Scaravilli 2, 40126 Bologna BO, Italy. E-mail: giulio.zanella@unibo.it
} 
Barczyk, 2016). No direct empirical evidence has been brought to bear on estimation of this parameter, nor are estimates for continental European countries available.

This paper provides a direct, structural estimate of the degree of intergenerational altruism in a Barro-type model (Barro, 1974) for Italy. Although different bequest motives (e.g., intergenerational altruism, exchange, strategic behavior) have been emphasized in the literature, we focus here on imperfect altruism à la Barro because of its conceptual simplicity and relevance in quantitative macroeconomic applications. We exploit the exogenous variation generated by reforms of inheritance taxation (estate tax, in the US) and taxes on inter vivos donations (gift tax, in the US), henceforth "bequest tax", ${ }^{1}$ that occurred in Italy between 2000 and 2001. This variation is exogenous (which greatly facilitates identification) because it is generated by tax reforms motivated by the 2001 electoral contest in Italy. We identify a degree of intergenerational altruism of between 0.2 and 0.3. This estimate refers to a large European country, is a direct counterpart of the existing estimates based on US data, and agrees by and large with the latter, suggesting that intergenerational altruism may be similar across advanced economies.

Besides providing a structural estimate of an important parameter for a large European country (certainly the first for Italy), this paper makes a number of contributions of general interest. First, our estimate is obtained in a general equilibrium setting exploiting the relationship between real estate (asset) prices, the change in bequest taxation, and bequest behavior emerging from the model. This approach connects the asset pricing perspective and the estimation of intergenerational altruism in a novel fashion. Second, and most important, we adopt a quasi-experimental method, exploiting an exogenous change of the bequest tax parameter fully leveraging the uniqueness of the Italian case. Such cases are uncommon and quite valuable; as Poterba (2001) puts it: "searching for additional sources of plausibly exogenous variation in the tax rates on gifts and bequests, and using such variation to study the elasticity of gift-giving, is a natural direction for further work" (p. 263). To the best of our knowledge, this paper is the first contribution to follow up on this suggestion in estimating one of the crucial determinants of gift-giving: intergenerational altruism. Finally, from a methodological viewpoint, we combine the pros of structural methods, calibration, and the quasi-experimental approach. These different empirical methods are often contrasted, but they can fit together quite well.

The quasi-experiment we exploit is the following. Until year 2000 the tax rate on bequests and donations in Italy had a progressive structure, as reported in Table 1, and was particularly unpopular. On October 13, 1999 the Italian Parliament rejected a bill, proposed by the conservative opposition leader Silvio Berlusconi, which aimed at repealing the tax. With a general election looming ahead in the Spring of 2001, the move of the opposition leader was clearly part of an early electoral campaign. As a consequence, the incumbent government was forced to act and

\footnotetext{
${ }^{1}$ Inheritance and gift taxes are often unified to prevent the use of donations as a mean to avoid the inheritance tax.
} 
reform the tax: two weeks later, the Finance Minister Vincenzo Visco announced that a reform of the inheritance and gift tax would be implemented "at the soonest, and in such a way that the tax rate will be single-digit". The government pushed through the Italian Parliament a reform as soon as the following month (December 1999), during the approval of the 2000 budget. This reform introduced a flat rate of $4 \%$ and increased the exemption threshold, and became effective at the end of 2000. The complete abolition of the inheritance and gift tax became a major issue in the political platform of the conservative coalition for the 2001 general election. In June 2001, only one month after the elections, the new government led by Silvio Berlusconi repealed the tax. Later on, in 2006, bequest taxation was reintroduced by the new center-left government led by Romano Prodi, at the same 2001 flat rate, but with such a high exemption threshold to make the tax immaterial.

Table 1: Bequest tax rates in Italy when the grantee is a spouse or direct relative

\begin{tabular}{cccc}
\hline \hline Legal reference & Tax base & Bracket & Rate (\%) \\
\hline Law 346/1990 & Total estate & $0-125 \mathrm{~K}$ & 0 \\
& & $125 \mathrm{~K}-175 \mathrm{~K}$ & 3 \\
& & $175 \mathrm{~K}-250 \mathrm{~K}$ & 7 \\
& $250 \mathrm{~K}-400 \mathrm{~K}$ & 10 \\
& & $400 \mathrm{~K}-750 \mathrm{~K}$ & 15 \\
& & $750 \mathrm{~K}-1500 \mathrm{~K}$ & 22 \\
& & $>1500 \mathrm{~K}$ & 27 \\
\hline Law 342/2000 & Estate per recipient & $0-175 \mathrm{~K}$ & 0 \\
& & $>175 \mathrm{~K}$ & 4 \\
\hline Law 383/2001 & & Any amount & 0 \\
\hline \hline
\end{tabular}

Notes: The table reports the bequest and inter-vivos donation tax rates in Italy before and after the 2000 and 2001 reforms. These rates refer to the case of a grantee who is either a spouse or a direct relative of the deceased or the donor. Rates for all other individuals are higher, see Jappelli et al. (2014) for more details.

In order to exploit these events and provide a structural estimate of the intergenerational altruism parameter, we built a unique panel data set using a variety of sources. The data set includes information on house prices, the housing stock, and non-housing consumption for the 13 largest cities in Italy over the period 1993-2004. The empirical investigation is based on a stylized OLG model in which individuals may either sell their assets or donate them to their offspring. The model formalizes a mechanism through which the bequest tax affects market (i.e., sales) and non-market (i.e., donations) real estate transactions, and the dynamics of house prices.

The key implication of the model for the purpose of identifying the parameter of interest is that, ceteris paribus, house prices respond to changes in the bequest tax rate if and only if the degree of intergenerational altruism is different from zero. Intuitively, a lower bequest tax rate makes asset donations more attractive to an altruistic parent, relative to liquidating the asset for own con- 
sumption purposes. Therefore, lowering bequest taxation drives up the shadow value of housing, thus increasing house prices and donations. ${ }^{2}$ The effects of bequest taxation on asset prices is not limited to housing. However, because of data availability and because of the special relevance of housing in intergenerational transfers, this asset is a natural target for structural estimation.

Heuristic evidence consistent with this economic mechanism is reported in Figure 1, which shows sales and donations per household, as well as the mean bequest tax rate and house prices in Italy between 1993 and 2004. When the bequest tax rate was sharply reduced, the number of donations per household increased almost threefold, to unprecedented levels, sales slowed down, and prices increased. ${ }^{3}$

The remainder of the paper is organized as follows: the model is built in Section 2, and it is first calibrated and then estimated in Section 3; Section 4 concludes.

Figure 1: Bequest tax rate, house prices, house donations, and house sales in Italy, 1993-2004.

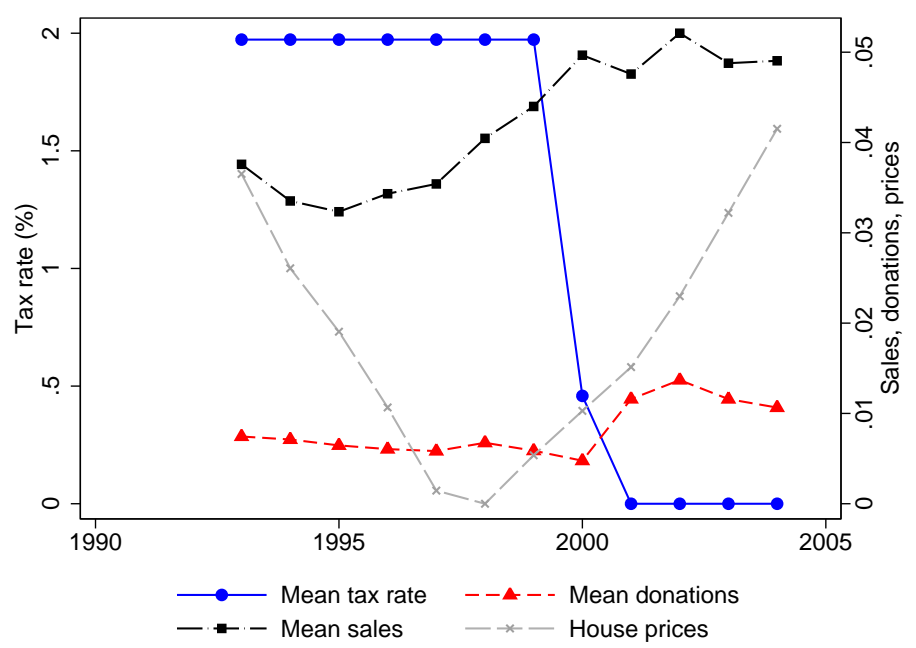

Notes: The figure shows the time series of the mean bequest tax rate, house donations and house sales per household in Italy between 1993 and 2004. The mean tax rate is computed as the weighted average across the different tax brackets in Table 1, using the empirical distribution of house prices reported in the Bank of Italy's Survey of Income Household and Wealth (missing values are interpolated). The price series is real and is represented on a log scale, in deviation from the minimum (11.388) and divided by 10 to fit in the picture (right scale). Other sources: NOMISMA for house prices, Italian Ministry of the Economy for donations and sales.

\footnotetext{
2 The distortionary effects of bequest taxation in the US have been investigated, among others, by Holtz-Eakin and Marples (2001), Kopczuk and Slemrod (2001), and Joulfaian (2006). The optimal structure of bequest taxation, a question that we do not address in this paper, has been studied by Farhi and Werning (2010). A baseline result is that in a model with a fictitious dynastic agent like the one we employ here, a zero bequest tax rate is optimal. Kopczuk (2009) provides an overview of theory and evidence.

3 In a companion paper to this one (Bellettini, Taddei, and Zanella, 2013) we perform a reduced-form regression analysis to estimate the effect of the tax reform on house sales and donations.
} 


\section{The model}

Our investigation is framed within a simple Barro-type model with imperfect altruism, augmented with a stylized housing sector. This is a natural benchmark for studying intergeneration altruism in relation to bequest taxes and house prices. Obviously this approach makes our estimate completely model-dependent, as is typically the case in structural estimation. Most important, this modeling choice restricts the form of the bequest motive in a non-trivial way, to the simplest formulation we can envision. This is intentional: by putting aside more sophisticated motives and more general forms of altruism we are giving the benchmark model a chance to reproduce in a transparent way the price dynamics and to provide an estimate of the altruism parameter that is in the ballpark of existing estimates based on more sophisticated models.

\subsection{Setup}

Consider a production economy with overlapping generations indexed by $j=1,2, \ldots$. These are sets of individuals of unit measure living for three periods, each period being composed of 30 years. During the first period (age 0-30, period 0), generation $j$ is inactive, is part of the older generation's household, and has no choices to make (so, effectively, there are only two periods in the model); during the intermediate period (age 31-60, period 1) generation $j$ is referred to as "young", it supplies inelastically one unit of labor, consumes $c_{1 j}$ units of a non-durable consumption good, and has children; in the final period (age 61-90, period 2) generation $j$ is referred to as "old", it is retired, consumes $c_{2 j}$ units of the consumption good, donates (possibly), and dies. In addition to these goods, each generation chooses, in period 1 , how much housing stock, $H_{j}$, to hold during the active lifetime. The preferences of generation $j$ are represented by

$$
\Upsilon_{j}=U_{j}(.)+\beta \rho \Upsilon_{j+1}
$$

where

$$
U_{j}=u\left(c_{1 j}\right)+\beta u\left(c_{2 j}\right)+v\left(H_{j}\right),
$$

and where $u(\cdot)$ and $v(\cdot)$ denote the utility derived from consumption of non-durable goods and housing, respectively, $\beta$ is a time preference factor, and $\rho$ is the degree of intergenerational altruism. We assume $u^{\prime}, v^{\prime}>0, u^{\prime \prime}, v^{\prime \prime}<0, \beta \in[0,1]$, and $\rho \in[0,1]$. Although we could treat housing like any other asset, we believe there are good reasons for having it in the utility function: this special asset is both a way of transferring wealth across time (and so across generations), and the source of a valuable good-housing services.

Notice that $\beta$ is a 30 -year discount factor: within a generation, the distance between period 
1 and period 2 is 30 years, and across generations the distance between period 2 of generation $j$ and the active life span (periods 1 and 2) of generation $j+1$ is also 30 years. This is a standard interpretation of OLG models that is used to express parameters at the appropriate frequencies (see, for instance, Nishiyama 2002). We will later refer to this interpretation when scaling back at the model (generational) frequencies the structural parameter of interest estimated at the different data (yearly) frequencies.

When young, individuals split their wealth (labor income plus after-tax bequests and donations received in the form of housing and non-housing transfers) between current consumption, nonhousing assets, purchase of existing houses and investment in new houses. When old, individuals split their wealth (savings and housing wealth) between consumption, and bequests and donations of either housing or the consumption good (the numeraire) to the following generation. Notice that bequests and donations are indistinguishable in this model (only the old can donate, to the young) and they both occur during the final period of a generation's life. In what follows we adopt the following convention, an innocuous abuse of notation that allows us to economize on words: we will refer to "period $j$ " as the period when generation $j$ is young, and to "period $j+1$ " as the period when generation $j$ is old (and so generation $j+1$ is young). The period budget constraints are:

$$
\begin{aligned}
& c_{1 j}=w_{j}-s_{j}+p_{j}\left[(1-\tau) H_{j-1}^{\text {don }}-H_{j}^{\text {used }}\right]+(1-\tau) D_{j-1}-i_{j}^{H} \\
& c_{2 j}=s_{j} R_{j+1}+p_{j+1} H_{j}^{\text {sale }}-D_{j},
\end{aligned}
$$

where $w_{j}$ is labor income, $s_{j}$ savings, $R_{j+1}$ the interest factor (one plus the interest rate), $p_{j}$ the price of a unit of the housing stock, $H_{j-1}^{d o n}$ the amount of housing that generation $j$ receives from generation $j-1, H_{j}^{u s e d}$ the amount of existing ("used") housing units held by generation $j$ in period $j, H_{j}^{\text {sale }}$ the amount of existing housing units sold by generation $j$ when old in period $j+1$, $i_{j}^{H}$ generation $j$ 's investment in new housing units, and $D_{j}$ the amount of the consumption good donated by generation $j$ to generation $j+1$ (i.e., the liquid asset). The government levies a bequest tax on intergenerational transfers: bequests or donations of either housing or the numeraire from the old to the young are taxed at rate $\tau \in[0,1]$. The tax revenue ends up outside the model.

Notice how equation (3) is constructed: $H_{j}^{\text {used }}$ is the number of existing ("used") housing units that generation $j$ acquires in period $j$ via both market transactions and non-market intergenerational transfers. Therefore, generation $j$ must satisfy the following, additional "accounting" constraints on housing:

$$
\begin{aligned}
H_{j}^{\text {used }} & \leq H_{j-1}^{\text {sale }}+H_{j-1}^{\text {don }} \\
H_{j}(1-\delta) & \geq H_{j}^{\text {sale }}+H_{j}^{\text {don }}
\end{aligned}
$$


where $\delta$ is the depreciation rate of the housing stock held by generation $j$. Inequality (5) means that consumption of housing by generation $j$ cannot exceed the sum of what is acquired via market and non-market transactions; inequality (6) means that that generation $j$ decides, when old in period $j+1$, how to allocate its depreciated stock of housing, $H_{j}(1-\delta)$, between donation to generation $j+1$ and resale on the market.

There are two production functions; one for houses, which uses non-durable goods as the only input and which exhibits decreasing returns,

$$
H_{j}^{\text {new }}=f\left(i_{j}^{H}\right), \text { with } f^{\prime}>0, f^{\prime \prime}<0
$$

where $H_{j}^{\text {new }}$ is the supply of newly produced housing units as a function of generation $j$ investment in housing, $i_{j}^{H}$; and one for the non-durable good itself, which uses non-housing capital and labor as inputs, and which exhibits the usual properties of aggregate production functions,

$$
\begin{gathered}
y_{j}=g\left(k_{j}\right), \\
g^{\prime}>0, g^{\prime \prime}<0,
\end{gathered}
$$

where $y_{j}$ and $k_{j}$ are output and non-housing capital per worker, respectively, in period $j$. We assume that the new housing units produced by one generation become part of the housing stock of that same generation. Non-housing capital (capital, for brevity) is created at no cost from the period $j$ consumption good, and is employed to produce consumption goods at $j+1$. We assume that capital fully depreciates in one period, so the law of motion of the per worker capital stock is

$$
k_{j+1}=i_{j}
$$

where $i_{j}$ is per worker investment in non-housing capital in period $j$. As usual, output is split between households and the government. The bequest tax is the only source of government revenue in this economy. We impose the additional constraints $H_{j}^{d o n} \geq 0$ and $D_{j} \geq 0$ (i.e., bequests cannot be negative) and focus, in what follows, on the interior optimum for all of the choice variables. ${ }^{4}$ In order to keep the empirical analysis simple and transparent, we also assume perfect forecast about future house prices.

\subsection{Equilibrium}

Definition 1 (Competitive equilibrium). The competitive equilibrium is a vector $\left(c_{1 j}, c_{2 j}, i_{j}, i_{j}^{H}\right.$, $\left.H_{j}, H_{j}^{\text {sale }}, H_{j}^{\text {don }}, H_{j}^{u s e d}, D_{j}\right)$ such that, given the price vector $\left(p_{j}, R_{j+1}, w_{j}\right)$ :

\footnotetext{
${ }^{4}$ This assumption is justified by the empirical goal of the paper: our representative agent is always at an interior in our data set.
} 
(i) Agents optimize:

$$
\left(c_{1 j}, c_{2 j}, i_{j}, i_{j}^{H}, H_{j}, H_{j}^{\text {sale }}, H_{j}^{\text {don }}, H_{j}^{u s e d}, D_{j}\right) \in \arg \max \Upsilon_{j} \text { s.t. (3), (4), (5), (6), } \forall j \text {. }
$$

(ii) The goods market clears:

$$
c_{1 j}+c_{2 j-1}+i_{j}^{H}+i_{j}+\tau\left(p_{j} H_{j-1}^{d o n}+D_{j-1}\right)=g\left(k_{j}\right) .
$$

(iii) The housing market clears:

$$
H_{j}=H_{j}^{u s e d}+H_{j}^{n e w}
$$

(iv) The capital market clears:

$$
k_{j+1}=s_{j}
$$

Notice that in equilibrium both (5) and (6) are binding - no valuable housing stock goes wasted, except because of depreciation. Combining these two and (12) we obtain the dynamic equation that describes the evolution of the housing stock:

$$
H_{j}=H_{j-1}(1-\delta)+f\left(i_{j}^{H}\right)
$$

It is easy to show that this equilibrium is self-consistent. Denoting the tax revenue by $T_{j} \equiv$ $\tau\left(p_{j} H_{j-1}^{d o n}+D_{j-1}\right)$ and using (11), we have:

$$
c_{1 j}+i_{j}^{H}+T_{j}+i_{j}=g\left(k_{j}\right)-c_{2 j-1} .
$$

Using equation (4), this yields:

$$
s_{j-1} R_{j}=g\left(k_{j}\right)-w_{j}=c_{2 j-1}+D_{j-1}-p_{j} H_{j-1}^{\text {sale }},
$$

so that equation (15) becomes:

$$
i_{j}=w_{j}+D_{j-1}-p_{j} H_{j-1}^{\text {sale }}-c_{1 j}-i_{j}^{H}-T_{j}
$$

Substituting for (9), we obtain:

$$
k_{j+1}=w_{j}-c_{1 j}+D_{j-1}-p_{j} H_{j-1}^{\text {sale }}-i_{j}^{H}-\tau\left(p_{j} H_{j-1}^{d o n}+D_{j-1}\right),
$$

and so, by (3) and (5), $k_{j+1}=s_{j}$, which completes the description of the model. 


\subsection{House prices}

Solving the maximization problem for generation $j$ and substituting the first-order conditions for $H_{j}^{u s e d}$ and $H_{j}^{\text {sale }}$ into the one for $H_{j}$ we obtain:

$$
v^{\prime}\left(H_{j}\right)=p_{j} u^{\prime}\left(c_{1 j}\right)-p_{j+1} \beta u^{\prime}\left(c_{2 j}\right)(1-\delta)
$$

This equation has a very simple interpretation: it states that generation $j$ equalizes the marginal benefit of consuming an additional unit of housing (LHS of the equation) to its marginal cost (RHS), where the latter is given by the difference between the utility-weighted cost of purchasing housing, $p_{j} u^{\prime}\left(c_{1 j}\right)$, and the utility-weighted benefit of reselling it when old, net of depreciation, $p_{j+1} \beta u^{\prime}\left(c_{2 j}\right)(1-\delta)$. A similar equation can be derived with respect to the optimal amount of donations, by substituting the first-order conditions for $H_{j}^{d o n}$ into the one for $H_{j}$ :

$$
v^{\prime}\left(H_{j}\right)=p_{j} u^{\prime}\left(c_{1 j}\right)-p_{j+1} \beta \rho(1-\tau)(1-\delta) u^{\prime}\left(c_{1 j+1}\right)
$$

Equation (20) can be interpreted as the equality between the marginal benefit of consuming an additional unit of housing (LHS) and its marginal cost (RHS), measured by the difference between the utility-weighted cost of purchasing housing (first term on the RHS) and the utility-weighted benefit of donating it to generation $j+1$ net of taxation and depreciation (second term on the RHS).

Taking equations (19) and (20) together, it is easy to see that at the competitive equilibrium the old generation will choose levels of consumption and donations so that its marginal utility equates the marginal utility of consumption of the following generation, weighted by the degree of intergenerational altruism, and after netting out the effect of bequest taxation:

$$
u^{\prime}\left(c_{2 j}\right)=\rho(1-\tau) u^{\prime}\left(c_{1 j+1}\right)
$$

Combining equation (21) with the first-order condition for optimal savings $s_{j}$,

$$
u^{\prime}\left(c_{1 j}\right)=\beta R_{j+1} u^{\prime}\left(c_{2 j}\right)
$$

we obtain:

$$
\frac{u^{\prime}\left(c_{1 j}\right)}{u^{\prime}\left(c_{1 j+1}\right)}=\beta \rho(1-\tau) R_{j+1} .
$$

Equation (23) summarizes the dynamic behavior of the economy. Since $R_{j+1} \geqslant 1$ and $\beta \rho(1-$ $\tau) \leqslant 1$, the right-hand side could be greater, equal or smaller than 1 . If $\beta \rho(1-\tau) R_{j+1}>1$ then consumption of the young increases from one generation to the next. If instead $\beta \rho(1-\tau) R_{j+1}<1$ 
then consumption of the young decreases from one generation to the next. We assume the economy is at its steady state, which is defined as follows:

Definition 2 (Steady state). For all $j$,

$$
\begin{aligned}
c_{1 j} & =c_{1 j+1}=c_{1}, \\
c_{2 j} & =c_{2 j+1}=c_{2}, \\
H_{j} & =H .
\end{aligned}
$$

Since $R_{j+1}$ is an endogenous price, in the steady state it must adjust so that $u^{\prime}\left(c_{1 j}\right)=u^{\prime}\left(c_{1 j+1}\right)$. By replacing this condition into (23), we obtain:

$$
R=\frac{1}{\beta \rho(1-\tau)}
$$

Combining this equation with (19) and (22), we obtain the key steady-state asset price equation for the housing stock:

$$
p=\frac{v^{\prime}(H)}{u^{\prime}\left(c_{1}\right)[1-\beta \rho(1-\delta)(1-\tau)]},
$$

This asset price equation can be used in combination with the first-order conditions for $i_{j}^{H}$ and $H_{j}^{u s e d}$ to determine the steady state level of housing investment, $i^{H}$. The latter solves

$$
p=\frac{1}{f^{\prime}\left(i^{H}\right)} .
$$

The steady-state effect of changes in the bequest tax rate $\tau$ is characterized by the following proposition and its corollary.

Proposition 1 (Effect of bequest taxes on steady-state house prices). If $\rho>0$ and if a lower interest rate does not induce lower consumption in the first period of the life cycle, then the steady-state house price, $p$, increases as the tax rate on bequests, $\tau$, decreases.

Proof. Rewriting (28) as

$$
\frac{p u^{\prime}\left(c_{1}\right)}{v^{\prime}(H)}=\frac{1}{[1-\beta \rho(1-\tau)(1-\delta)]},
$$

we see that when $\tau$ decreases, $p u^{\prime}\left(c_{1}\right) / v^{\prime}(H)$ must increase for this equation to be satisfied. By equation (27), a decrease in $\tau$ decreases $R$. Suppose a lower $R$ increases $c_{1}$ (and so decreases $\left.u^{\prime}\left(c_{1}\right)\right)$. Because $u^{\prime}\left(c_{1}\right)$ decreases, the $p / v^{\prime}(H)$ ratio must increase. Suppose $p$ does not change. Then $v^{\prime}(H)$ decreases, which means that $H$ increases, because $v(\cdot)$ is concave. But by (14) this is possible only if $i^{H}$ also increases. Then $f^{\prime}\left(i^{H}\right)$ must decrease and, by (29), $p$ increases, contradicting the assumption that $p$ does not change. Now suppose that $p$ decreases. Then $v^{\prime}(H)$ must 
decrease even faster, which means that $H$ increases. But this yields a contradiction too, because by (29) $p$ must then increase. Therefore, $p$ must increase.

Corollary 1 (Effect of bequest taxes on steady-state housing investment and stock). Under the same conditions of Proposition 1, as the tax rate on bequests, $\tau$, decreases, residential investment and the housing stock increase.

Proof. Follows directly from equation (29).

Proposition 1 has a straightforward economic interpretation. For the old, the housing stock can be employed in two ways: it can either be sold on the market or it can be transferred directly to the next generation, net of the ad valorem transfer tax. When the tax rate is reduced, there are two effects. First, standard income and substitution effects. These work in the same direction, bringing about an increase in donations and house prices. Second, a general equilibrium effect via the interest rate. A lower bequest tax rate requires, in equilibrium, a lower interest rate because one must be indifferent (after factoring in $\rho$ ) between donating assets and saving (a "no arbitrage" requirement, see equation 27). However, since in the first period an individual is a net saver, the effect of a higher interest rate on period 1 consumption - and so on donations - is ambiguous. If, in response to the general equilibrium effect (lower $R$ ), period 1 consumption increases, then house prices unambiguously increase. ${ }^{5}$

\section{Empirical analysis}

The empirical analysis consists of a preliminary calibration exercise as a check on the model's ability to replicate house price dynamics at the city level, and then structural estimation of intergenerational altruism in such a model. The starting point is the annual analog of equation (28):

$$
p_{t}=\frac{v^{\prime}\left(H_{t}\right)}{u^{\prime}\left(c_{1 t}\right)\left[1-\beta \rho(1-\delta)\left(1-\tau_{t}\right)\right]},
$$

where $t$ indexes years. Notice the difference between the time index $t$ and the generation index $j$ : equation (28) represents the steady state, and is derived from a model cast at low (generational) frequencies, while equation (31) represents the same steady state at higher (annual) frequencies, and is used to conduct our empirical investigation. This difference is dictated by data availability, as we cannot observe house prices, the housing stock, and consumption of the young one generation ahead, as would be needed to estimate the transitional dynamics. This data constraint challenges

\footnotetext{
${ }^{5}$ Notice that, a fortiori, this result would still hold if we had assumed a small open economy where the relevant interest rate is the (exogenous) world rate of return on savings. In this case, too, an increase in house prices is needed to restore the equality between the return on housing and the fixed return on capital holdings.
} 
inference on $\rho$ based on equation (31) only if following the tax change the economy does not jump to the new steady state. The speed of convergence is entirely an empirical matter. The calibration exercise performed below suggests that, in fact, convergence to the new steady state takes place fast, which justifies the use of the steady-state equation for our empirical analysis. To put it another way, suppose that the model is true but it took a long time to reach the new steady state. Then only the equation describing the transitional dynamics would have a chance in replicating the annual data in a calibration exercise. As it turns out, the steady state equation does a good job at replicating the data. This implies that the economy (when interpreted through the lenses of the model) is not far from the steady state, ${ }^{6}$ and so the steady state equation provides a fair approximation of the behavior of the economy for an empirical analysis at the annual frequency. That is, the fit produced by the calibration exercise justifies, ex-post, the use of the steady state equation. The only caveat, as pointed out in Section 2.1 , is that the parameter we estimate at the yearly frequencies must be rescaled on a 30-year basis (half the active life span in the model) to be interpreted at the lower, generational frequencies of the model.

\subsection{Data set}

We collected data from a variety of sources, which we use to construct a city-level panel data set for the period 1993-2004. City-level real estate prices, market transactions, and residential stocks come from the NOMISMA data base, a proprietary archive. This data base contains average prices of new and used residential units per square meter. We focus on the price of a used unit of average size (this is the notion of residential unit that is consistent with the model), where average size is taken from the 2001 Italian Census. Data on donations were provided by the Italian Ministry of the Economy. We use the Bank of Italy's Survey of Household Income and Wealth (SHIW) to estimate non-housing consumption. This is defined as total household expenditure in durables and non-durables, excluding rents and maintenance expenses. ${ }^{7}$ House prices and non-housing consumption are deflated using the CPI, and are expressed in constant 1993 euros. Table 2 contains key summary statistics from our sample.

\footnotetext{
${ }^{6}$ An alternative explanation of this empirical fact is that agents don't have rational expectations.

${ }^{7}$ Consumption data is also available in the much larger Household Consumption Expenditure survey maintained by ISTAT, the Italian Statistical Office. However, the publicly available version of these data do not allow us to identify the consumption aggregate that is relevant in the model: consumption of households whose head is between 31 and 60 years of age.
} 
Table 2: Summary statistics

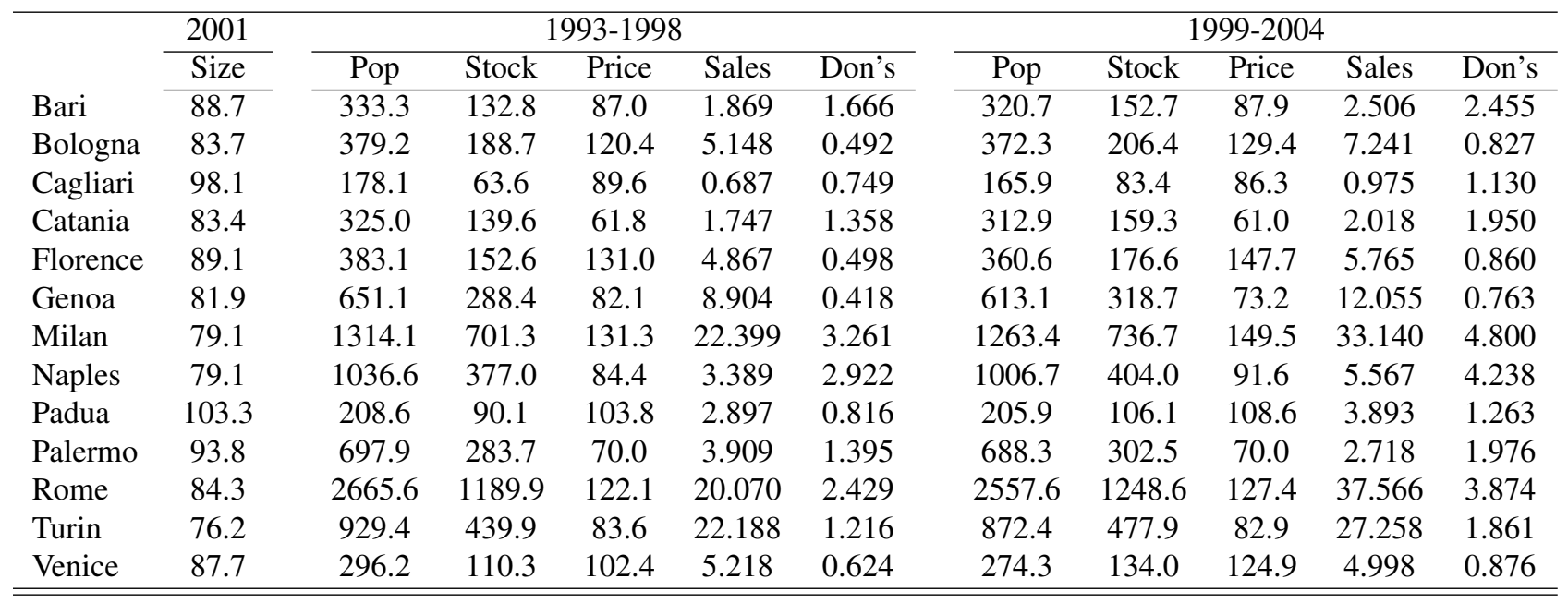

Notes: The table reports, in the first column, the average size of housing units in 2001 (source: 2001 Italian Census); the remaining columns contain population and annual averages of stocks, prices, and transactions in two periods: 1993-1998 and 1999-2004. Legend: Pop = city population; Stock = housing units; Price: price of a used housing unit of average size, in thousands of constant 1993 euros; Sales = number of market transactions; Don's = number of non-market transactions (donations). All figures except size are in thousands.

\subsection{Calibration}

The goal of the calibration exercise is to replicate the observed price series in the sample using the asset price equation (31). Notice that this is enough to check the consistency between the model and the data because this equation subsumes all of the other first-order conditions as well. It turns out that the model-based steady state relationship provides a good fit of the annual time series. Incidentally, by focusing on prices, the calibration exercise produces a model-based estimate of the effect of the reform on house prices, which be briefly comment below.

Taking $\operatorname{logs}$, we can write condition (31) as:

$$
\ln p_{t}=\ln \frac{v^{\prime}\left(H_{t}\right)}{u^{\prime}\left(c_{1 t}\right)}-\ln \left[1-\beta \rho(1-\delta)\left(1-\tau_{t}\right)\right]
$$

Taking a first-order Taylor expansion of the utility function around the steady state of the current cohort, $\left(H^{*}, c_{1}^{*}\right),{ }^{8}$ or, equivalently, assuming directly a log specification for the utility function

${ }^{8}$ One can express marginal utility as

$$
v^{\prime}\left(H_{t}\right) \approx \frac{v^{\prime}\left(H^{*}\right) H^{*}}{H_{t}} ; u^{\prime}\left(c_{1 t}\right) \approx \frac{u^{\prime}\left(c_{1}^{*}\right) c_{1}^{*}}{c_{1 t}}
$$

and $\alpha \equiv \ln \left[v^{\prime}\left(H^{*}\right) H^{*}\right]-\ln \left[u^{\prime}\left(c_{1}^{*}\right) c_{1}^{*}\right]$ in equation (32). These expression follow from the fact that, for any function 
in $(2),{ }^{9}$ we can rewrite (32) as

$$
\ln p_{t}=\ln c_{1 t}-\ln H_{t}+\alpha-\ln \left[1-\beta \rho(1-\delta)\left(1-\tau_{t}\right)\right]
$$

where $\alpha$ is an unobserved city effect. For the purposes of calibration, we use the first-differenced version of equation (33) to eliminate the city effect:

$$
\Delta \ln p_{i t}=\Delta \ln c_{1, i t}-\Delta \ln H_{i t}-\Delta \ln \left[1-\beta \rho(1-\delta)\left(1-\tau_{t}\right)\right]
$$

We calibrate the model parameters as follows. First, for the annual discount factor we set $\beta=0.96$. Second, we set $\delta=0.0275$. This value is taken from Harding, Rosenthal and Sirmans (2007), who estimate from the American Housing Survey that the housing stock depreciates at between $2.5 \%$ and $3 \%$ per year in the US.

Third, to calibrate $\rho$ we draw from the studies mentioned in the Introduction. In Nishiyama (2002) adult life lasts 60 years like in our model, and he obtains $\rho=0.512$ when the coefficient of relative risk aversion is set equal to 2 and $\rho=0.388$ when this coefficient is equal to 4 . Han and Mulligan's (2001) estimate is $\rho=0.295$, and Barczyk's (2016) is $\rho=0.280$ for the old household that is the counterpart of the old household in our model. The average of these estimates is 0.368 , implying a value of 0.967 at an annual frequency (i.e., $0.368^{1 / 30}$ ). These values imply $\beta \rho(1-\delta)=$ 0.928 for yearly data.

Fourth, we need to estimate the relevant bequest tax rate, $\tau$. In the model, this is the rate applied to the value of the marginal housing unit that is transferred to the young generation. We assume that this marginal housing unit is equal to the average housing unit (i.e., there is no selectivity inducing systematic differences between those housing units that are donated to one's offspring and those that are not). Under this assumption, $\tau$ can be computed as a weighted average across the different tax brackets reported in Table 1, using the frequencies from the empirical distribution of house prices as weights. Such empirical distribution is taken from the 2000 cross-section of the SHIW (pre-reform values) in order to keep weights constant. The result is an average tax rate of $1.97 \%$ until $1999,0.46 \%$ in 2000 , and $0 \%$ from 2001 to $2004 .^{10}$

$f(x)$ and approximation point $x^{*}$,

$$
f(x) \approx f\left(x^{*}\right)+f^{\prime}\left(x^{*}\right)\left(x-x^{*}\right)=f\left(x^{*}\right)+f^{\prime}\left(x^{*}\right) x^{*}\left(\ln x-\ln x^{*}\right) \Rightarrow f^{\prime}(x) \approx \frac{f^{\prime}\left(x^{*}\right) x^{*}}{x}
$$

\footnotetext{
${ }^{9}$ Notice that such an approximation or its equivalent parametric assumption implicitly pick a special case among those considered in Proposition 1, namely the case in which "a lower interest rate does not affect consumption in the first period".

${ }^{10}$ The rates in Table 1 refer to inheritances by and donations to one's spouse and direct relatives, which cover virtually all cases.
} 
Fifth, a young household is defined as a household whose head is between 31 and 60 years old, and from the SHIW, we compute mean non-housing consumption for these households, $c_{1}$. This is defined as total household expenditure in durables and non-durables, excluding rents (actual and imputed) and maintenance expenses (ordinary and extraordinary). ${ }^{11}$ Unfortunately, the lowest level of aggregation at which information in the SHIW is publicly released is the region. ${ }^{12}$ The best we can do is to attribute to each city the average household consumption of the region where the city is located. Presumably, this procedure leads to underestimation of the level of city consumption because income and consumption expenditure are lower is non-urban areas. However, it is not obvious that the resulting growth rate is also biased.

Finally, $H$ is measured by the number of housing units (the housing stock) at the city level, as estimated at the annual frequency by ISTAT, the Italian Statistical Office. The housing stock is missing for years prior to 2000, and missing values are predicted using the coefficients from a linear projection of the housing stock on city population, city dummies, and a linear time trend for the period 2000-2012.

We simulate the model from 1995 onward, because the fit is poor in 1993 and 1994. The result of the exercise is reported in Figure 2. This figure shows three different price series. First, the data. Second, the series generated by equation (34). Third, the counterfactual series generated by this equation when the tax rate is left unchanged at the pre-2000 level. Notice that in the model prices adjust immediately. Therefore, in Figure 2 changes in the bequest tax rate have a permanent level effect and a transitory growth effect in 2000 and 2001. Considering that we are using a very parsimonious theory, the model reproduces the data fairly well. In particular, we are able to reproduce the turning point in the price series quite accurately in most cities. The only exceptions are Venice and Genoa. The model with tax changes clearly outperforms the counterfactual with an unaltered bequest tax: the distance between model and data, measured in mean square differences across cities, is 0.023 and 0.062 , respectively.

The difference between the model's prediction with the actual tax change and the counterfactual prediction when the tax rate is held constant at the pre-2000 level is a model-based estimate of the effect of the tax reduction. As shown in Table 3, this difference is $12.7 \%$ in 2000 and $4.1 \%$ in 2001. Because the tax reduction was 1.514 and 0.458 percentage points, respectively, these numbers correspond to a semi-elasticity of about $8 \%$. This is admittedly a large number. It means that a 1 percentage point reduction of the average (weighted) bequest tax induces a $8 \%$ increase in house prices. In a companion paper to this one (Bellettini, Taddei, and Zanella, 2013), we conduct an event study of the reforms and produce a reduced-form estimates of about $5 \%$, corresponding to

\footnotetext{
${ }^{11}$ Sampling weights are applied. The frequency of the SHIW is biennial, with the exception of a two-year lag between 1995 and 1998. All missing years are interpolated linearly.

12 There are 20 administrative regions in Italy.
} 
Figure 2: House prices: actual and generated by calibrated asset price equation
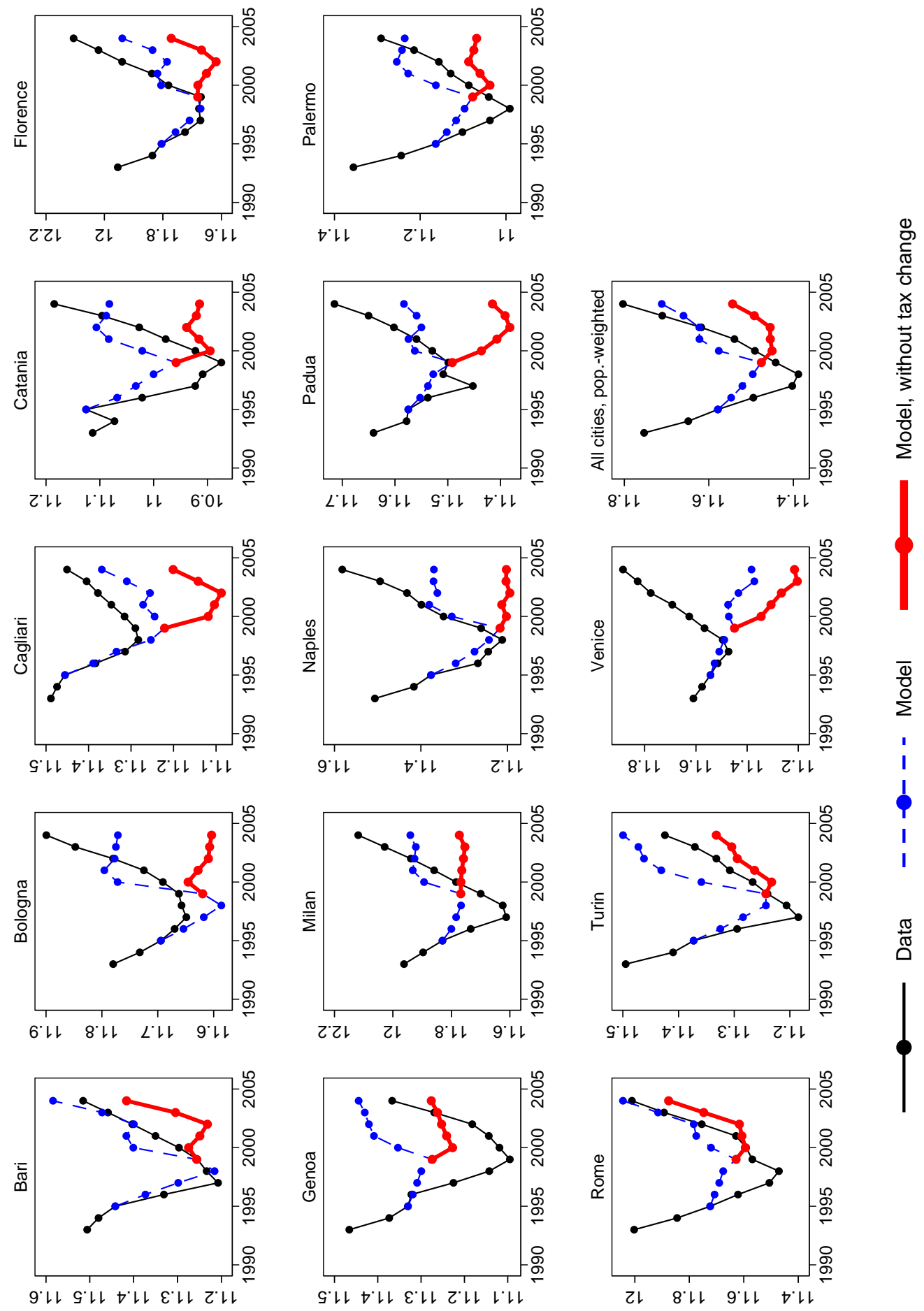

Notes: The figure compares the house price data with two model generated-series: the first is generated by the model when we consider the actual tax changes; the second is generated by the model in the counterfactual situation of no tax changes during the 1993-2004 period. 
a semi-elasticity of about $2.5 \%$. This is much smaller than the model-based effect. In interpreting the latter, however, one must keep in mind that there are no frictions in the model—prices adjust immediately. In reality, housing market frictions are likely to attenuate this impact effect. Therefore, a way of interpreting the discrepancy between the model-based (8\%) and the reduced-form $(2.5 \%)$ semi-elasticity of house prices to the bequest tax rate is that frictions (either optimization frictions or market frictions strictly defined, or both) are possibly important during the adjustment to a new tax regime. Given the model's ability to replicate the data fairly well, we turn to structural estimation of the main parameter of interest, $\rho$, in this model.

Table 3: Average variation in house prices in 2000 and 2001

\begin{tabular}{llcc}
\hline & & 2000 & 2001 \\
\cline { 2 - 3 } (a) Data & 0.049 & 0.046 \\
(b) Model, with tax change & 0.085 & 0.033 \\
(c) Model, no tax change & -0.042 & -0.008 \\
\cline { 2 - 3 } & Difference $((\mathrm{b})-(\mathrm{c}))$ & 0.127 & 0.041 \\
\hline \hline
\end{tabular}

Notes: The table reports the cross-city average of $\Delta \ln p_{i t}$ in 2000 and 2001. In these years the bequest tax rate was reduced, which implies a transitory growth effect in the two years. The difference between the average variation in the model and the corresponding variation when the tax rate is held constant (i.e., (b)-(c)) is a model-based estimate of the effect of the reduction in bequest taxation on house prices.

\subsection{Identification and structural estimation}

Equation (33) can be estimated on our panel introducing a cross-sectional dimension $(i)$, and an error term representing random shocks to preferences, or technology, or both $\left(\varepsilon_{i t}\right)$ :

$$
\ln p_{i t}=\alpha_{i}-\ln \left[1-\beta \rho(1-\delta)\left(1-\tau_{t}\right)\right]-\ln H_{i t}+\ln c_{1, i t}+\varepsilon_{i t}
$$

This is a constrained, nonlinear regression with coefficients on $\ln H_{i t}$ and $\ln c_{1, i t}$ set equal to -1 and 1 , respectively, which is equivalent to estimating the following equation,

$$
\ln \left(p_{i t} H_{i t} / c_{1, i t}\right)=\alpha_{i}-\ln \left[1-\beta \rho(1-\delta)\left(1-\tau_{t}\right)\right]+\varepsilon_{i t},
$$

a specification in which the dependent variable is the log of the ratio of housing consumption to non-housing consumption. Notice that the tax rate varies over time only, not across cities. Therefore, the city effect $\alpha_{i}$ is uncorrelated with $\tau_{t}$ and must be treated as a random effect. Specification (36) is, of course, the direct empirical counterpart of the model's first-order conditions. That is, we estimate the asset pricing equation as produced by the model, without engaging in any explicit 
or implicit "specification search". Because the only time-varying variable on the RHS (besides the error term) is the bequest tax rate, the credibility of our identification rests upon the credibility of the exogenous nature of the tax reforms we are considering. As discussed in Section 1, the reforms were motivated by the electoral competition and so it is reasonable to assume that they were exogenous with respect to asset prices. If one believes this identifying assumption, then there are no identification issues under specification (36), provided one takes care of serial correlation in the panel. In other words, all factors affecting house prices during the period under investigation (e.g., time trends, demographic changes, secular changes in demand or supply of housing, changes in real interest rates, etc.) are already factored into Equation (36), either in the error term (which is uncorrelated with $\tau_{t}$ ) or in the $H_{i t} / c_{1, i t}$ term. The latter, in particular, captures intertemporal factors affecting house prices. Nonetheless, in order to provide a more conservative estimate, we employ as a robustness check specifications where flexible, city-specific quadratic or quartic trends are added to equation (36). The resulting estimate of $\rho$ will be less tight because of the large number of additional parameters to be estimated, but this provides a check against other possible timevarying determinants of house prices not fully captured by the housing-to-consumption ratio, for instance because the latter is measured with error.

Even after performing such a robustness check, a residual source of concern may be the following. Suppose that, in reality, $\rho=0$ and there are unobserved (or simply unaccounted for) events at the national level that occurred exactly at the same time as the bequest tax reform, and that affected house prices in the same direction as the model predicts the tax change would when $\rho>0$. In this case, because our identification is effectively based on a before-after comparison in a time series setting, our estimate would be misleading. ${ }^{13}$

In the absence of a control group (the reform affected all Italian cities equally), some evidence limiting this concern comes from the companion paper to this one. Bellettini, Taddei, and Zanella (2013) shows in a reduced-form regression framework that the reform increased donations and reduced sales between 2001 and 2004, as predicted by the model. Although not conclusive, this evidence corroborates the claim that the effect we identify is, in fact, driven by a change in $\tau_{t}$ and not some unobserved variable. While possible, it strains credibility that a one-time, permanent change in some other variable that was relevant for house prices took place at exactly the same time as the tax reform and was also altering the value of donations. If relevant, such an event would not have gone unnoticed.

The Non-linear Least Squares (NLS) estimation of equation (36) identifies the composite structural parameter $\beta \rho(1-\delta)$. The latter, in turn, for plausible values of the depreciation rate $\delta$ and the intertemporal discount factor $\beta$, allows us to recover a range of plausible values for the struc-

\footnotetext{
${ }^{13}$ We are not aware of such major events. The Euro began circulating in 2001, but it was adopted in 1999. The convergence of interest rates had started much earlier and was essentially completed by 2000-2001.
} 
tural parameter of interest, $\rho$. We measure $\tau_{t}$ as explained in Section 3.2, and we assume that the tax change is not anticipated. ${ }^{14}$

The intermediate results are reported in Table 4. Column 1 is the baseline specification, and the remaining 4 columns report the results of robustness checks that are consistent with the model structure: in column 2, the regression is weighted by city population; in column 3, Genoa and Venice (the two cities for which the fit from the calibration exercise is poor, see Figure 2) are excluded; in column 4, a deterministic, quadratic time trend is included; in column 5, the time trend is modeled as a fourth-order polynomial in time. Our point estimate of the composite parameter $\beta \rho(1-\delta)$ ranges between 0.751 and 0.921 across these different specifications, with a small standard error. It is remarkable that in specification 5 the tax change keeps its explanatory power even after superimposing a quartic trend that absorbs a lot of variation in the price series, as the large increase in $R^{2}$ shows.

In order to back out $\rho$, we need values for the annual discount factor and depreciation rate. Consistent with the calibration exercise, we set $\beta=0.96$; as for $\delta$, we let this parameter take three possible values: $1 \%, 2 \%$, and $3 \%$. The resulting estimate of $\rho$ is at the annual frequencies, and so it needs to be rescaled at the generational frequencies to be interpretable within the model, as discussed in Section 2.1. Denoting the estimate at the annual frequency by $\rho_{A}$ and the estimate at the generational frequency by $\rho_{G}$, rescaling simply takes the form $\rho_{G}=0.96^{30} \rho_{A}$, because 30 years is the distance between period 2 of generation $j$ (when a donation takes place) and the active life span (periods 1 and 2) of generation $j+1$ (when the donation produces utility to the receiver). The resulting estimates of the intergenerational altruism parameter at the generational frequency are reported in Table 5 for the largest and the smallest point estimates of the composite parameter, and range between 0.22 and 0.28 .

\section{Conclusion}

In this paper we have exploited a reform of bequest taxation in Italy to identify the degree of intergenerational altruism in a standard OLG framework with imperfect altruism as the only bequest motive. This is, to the best of our knowledge, the first paper that provides a direct, structural estimate of such a parameter by means of an exogenous variation in bequest taxation. Our direct

\footnotetext{
${ }^{14}$ Insofar as it is partly anticipated (as the evidence in Bellettini, Taddei, and Zanella, 2013, suggests), our estimate of $\rho$ should be interpreted as a lower bound for the degree of intergenerational altruism. If the reform is anticipated then the reform-induced change in prices from just before to just after the reform would be smaller than the overall reform-induced price change: anticipation would cause the observed and the counterfactual price series to diverge before the reform is implemented, thus leading to underestimation of the causal effect of the tax change on house prices, and so to underestimation of $\rho$.
} 
Table 4: Estimation of the model's structure

\begin{tabular}{lccccc}
\hline & 1 & 2 & 3 & 4 & 5 \\
\cline { 2 - 6 }$\beta \rho(1-\delta)$ & $0.921^{* *}$ & $0.910^{* *}$ & $0.916^{* *}$ & $0.910^{* *}$ & $0.751^{* *}$ \\
& $(0.013)$ & $(0.014)$ & $(0.010)$ & $(0.037)$ & $(0.096)$ \\
Constant & 0.041 & 0.210 & 0.138 & 0.227 & $1.235^{* *}$ \\
& $(0.138)$ & $(0.139)$ & $(0.091)$ & $(0.427)$ & $(0.399)$ \\
\hline Observations & 156 & 156 & 132 & 156 & 156 \\
Adjusted $R^{2}$ & 0.13 & 0.05 & 0.16 & 0.80 & 0.97 \\
Cities & 13 & 13 & 11 & 13 & 13 \\
Population-weighted & No & Yes & No & No & No \\
Additional time-trend & No & No & No & Quadratic & Quartic \\
\hline
\end{tabular}

Notes: Nonlinear Least Squares estimates of composite structural parameter $\beta \rho(1-\delta)$. The dependent variable is $\ln p_{i t} H_{i t} / c_{1, i t}$. Column 1 reports the baseline estimate; in column 2 , the regression is weighted by city population; in column 3 we exclude Genoa and Venice, for which the fit from the calibration exercise is poor (see Figure 3); in column 4 we include a deterministic quadratic time trend; in column 5 the trend is a quartic function of time. Standard errors are reported in parentheses, and are robust to heteroskedasticity and serial correlation at the city level. Statistical significance: $* 5 \%, * * 1 \%$ or better

Table 5: Estimates of the intergenerational parameter $\rho$

\begin{tabular}{|c|c|c|c|c|c|c|c|}
\hline Parameter & Freq. & \multicolumn{3}{|c|}{$\beta \rho(1-\delta)=0.751$} & \multicolumn{3}{|c|}{$\beta \rho(1-\delta)=0.921$} \\
\hline$\delta$ & 1 year & 0.01 & 0.02 & 0.03 & 0.01 & 0.02 & 0.03 \\
\hline $\begin{array}{c}\rho \\
\text { (s.e.) }\end{array}$ & 1 year & $\begin{array}{c}0.775 \\
(0.099)\end{array}$ & $\begin{array}{c}0.767 \\
(0.098)\end{array}$ & $\begin{array}{c}0.759 \\
(0.097)\end{array}$ & $\begin{array}{c}0.950 \\
(0.014)\end{array}$ & $\begin{array}{c}0.940 \\
(0.014)\end{array}$ & $\begin{array}{c}0.931 \\
(0.013)\end{array}$ \\
\hline $\begin{array}{c}\rho \\
\text { (s.e.) }\end{array}$ & 30 years & $\begin{array}{c}0.228 \\
(0.029)\end{array}$ & $\begin{array}{c}0.225 \\
(0.029)\end{array}$ & $\begin{array}{c}0.223 \\
(0.029)\end{array}$ & $\begin{array}{c}0.279 \\
(0.004)\end{array}$ & $\begin{array}{c}0.276 \\
(0.004)\end{array}$ & $\begin{array}{c}0.274 \\
(0.004)\end{array}$ \\
\hline
\end{tabular}

Notes: Estimates of the intergenerational altruism parameter, $\rho$, at the annual and generational frequency. For given values of $\delta$, the former is estimated as $\rho_{A}=\beta \widehat{\rho(1-\delta)} / \beta(1-\delta)$, where $\beta \widehat{\rho(1-\delta)}$ is the baseline NLS estimate reported in Table 4. The latter, instead, is computed as $\beta^{30} \rho_{A}$. Standard errors are computed using the delta method. 
estimate for Italy of between 0.22 and 0.28 is consistent with existing indirect ones for the US. This suggests that intergenerational altruism may be quite uniform across advanced economies. From a methodological viewpoint, we regard our contribution as an illustration of how one can fruitfully combine different empirical approaches (reduced-form analysis of quasi-experiments, structural methods, and calibration methods) to produce credible empirical evidence from tax reforms that is relevant for both theory and policy. Unanticipated tax reforms such as the one that we exploit are as uncommon as valuable. Poterba (2001) was already suggesting the need to use "sources of plausibly exogenous variation in the tax rates" to study the elasticity of gift-giving. This paper is the first contribution to follow up on this suggestion in estimating one of the crucial determinants of gift-giving: intergenerational altruism.

\section{References}

Barczyk, D. (2016), "Ricardian Equivalence Revisited: Deficits, Gifts, and Bequests", Journal of Economic Dynamics and Control, 63, 1-24.

Barro, R. (1974), “Are Government Bonds Net Wealth?”, Journal of Political Economy, 82(6), 1095-1117.

Bellettini, G., F. Taddei, and G. Zanella (2013), "Bequest taxes, donations, and house prices", $B E$ Journal of Macroeconomics, 13(1), 355-379.

Cannari, L. and G. D'Alessio (2008), "Intergenerational Transfers in Italy", in Household Wealth in Italy, Bank of Italy.

Farhi, E. and I. Werning (2007), "Inequality and Social Discounting", Journal of Political Economy, 115(3), 365-402.

Farhi, E. and I. Werning (2010), "Progressive Estate Taxation”, Quarterly Journal of Economics, $125(2), 635-673$.

Han, S., and C. Mulligan (2001), "Human Capital, Heterogeneity and Estimated Degrees of Intergenerational Mobility”, Economic Journal, 111(470), 207-243.

Harding, J., S. Rosenthal, and C. Sirmans (2007), "Depreciation of housing capital, maintenance, and house price inflation: Estimates from a repeat sales model", Journal of Urban Economics, 61(2), 193-217.

Holtz-Eakin, D. and D. Marples (2001), "Distortion Costs of Taxing Wealth Accumulation: Income Versus Estate Taxes", NBER Working Paper No. 8261. 
Jappelli, T., Padula, M. and G. Pica (2014), “Do Transfer Taxes Reduce Intergenerational Transfers?", Journal of the European Economic Association, 12(1), 248-275.

Joulfaian, D. (2006), “The Behavioral Response of Wealth Accumulation to Estate Taxation: Time Series Evidence", National Tax Journal, 59, 253-268.

Kopczuk, W. (2009), "Economics of Estate Taxation: a Brief Review of Theory and Evidence", Tax Law Review, 63(1), 139-157.

Kopczuk, W. and J. Slemrod (2001), "The Impact of the Estate Tax on the Wealth Accumulation and Avoidance Behavior of Donors", in Rethinking Estate and Gift Taxation, edited by W. G. Gale, J. R. Hines, and J. B. Slemrod, Brookings Institution Press.

Nishiyama, S. (2002), “Bequests, Inter Vivos Transfers, and Wealth Distribution”, Review of Economic Dynamics, 5(4), 892-931.

Poterba, J. (2001), "Estate and gift taxes and incentives for inter vivos giving in the US." Journal of Public Economics, 79(1), 237-264. 